\title{
CARACTERIZACIÓN PARCIAL DE UNA LIPASA EXTRACELULAR DE Marinobacter SP. EMPLEANDO LA METODOLOGÍA DE SUPERFICIE RESPUESTA
}

\author{
Partial characterization of an extracellular lipase from Marinobacter sp through response \\ surface methodology
}

Yadira Fernández-Jerí, Amparo I. Zavaleta, Luis Alejandro-Paredes, Victor Izaguirre

Laboratorio de Biología Molecular de la Facultad de Farmacia y Bioquímica. Universidad Nacional Mayor de San Marcos

\section{RESUMEN}

En la última década, se ha incrementado la demanda de enzimas de origen microbiano para diversos procesos industriales, por ello, el objetivo del estudio fue la caracterización bioquímica parcial de una lipasa extracelular de Marinobacter sp. aislado de las Salinas de Pilluana (San Martín), mediante la metodología de superficie respuesta. Se analizó el efecto de los factores: pH $(4,0-9,0)$, temperatura $\left(32,5-45,0^{\circ} \mathrm{C}\right)$, tiempo (o,o - 40,o min) y las concentraciones de $\mathrm{NaCl}(\mathrm{o}, \mathrm{O}-10,0 \%)$ y CaCl $2(0,0-1,0 \%)$, sobre la actividad específica de la enzima mediante el diseño estadístico experimental de Box-Behnken en tres niveles. Además, se determinaron las constantes catalíticas $\left(\mathrm{K}_{\mathrm{m}} \mathrm{y} \mathrm{V}_{\text {max }}\right)$ y la estabilidad térmica de la enzima. Los parámetros óptimos de reacción de la lipasa de Marinobacter sp. fueron $\mathrm{pH}$ 7,0; $37^{\circ} \mathrm{C}$ y 30 min, usando como sustrato p-NPP. La $\mathrm{V}_{\max }$ y el $\mathrm{K}_{\mathrm{m}}$ de la lipasa fueron 3,190o U/ mg y o,2428 mM, respectivamente. La actividad enzimática de la lipasa fue estable hasta $45^{\circ} \mathrm{C}$ durante $10 \mathrm{~min}$.

Palabras clave: Marinobacter sp, lipasa, metodología de superficie respuesta, p-nitrofenilpalmitato.

\section{SUMMARY}

In the last decade, has increased the demand for enzymes of microbial origin to diverse industrial processes. Therefore, the aim of these research was the partial biochemical characterization of an extracellular lipase of Marinobacter sp isolated from the Salinas de Pilluana (San Martin), using the response surface methodology. Were analyzed the effect of factors such as: $\mathrm{pH}(4, \mathrm{O}-9, \mathrm{o})$, temperature $\left(32,5-45, \mathrm{O}{ }^{\circ} \mathrm{C}\right)$, time $(\mathrm{o}, \mathrm{o}-40, \mathrm{o} \mathrm{min})$ and the concentrations of $\mathrm{NaCl}(\mathrm{o}, \mathrm{o}-10,0 \%)$ and $\mathrm{CaCl}_{2}(\mathrm{o}, \mathrm{O}-1,0 \%)$, on the specific activity through the Box-Behnken experimental statistical design employed in three levels. In addition, were determined the catalytic constants $\left(\mathrm{K}_{\mathrm{m}}\right.$ and $\left.\mathrm{V}_{\max }\right)$ and the thermal stability of the enzyme. The optimal reaction parameters to lipase from Marinobacter sp. were $\mathrm{pH} 7,0 ; 37^{\circ} \mathrm{C}$ and 30 min, using as substrate p-nitrophenyl palmitate. The $\mathrm{V}_{\max }$ and $\mathrm{K}_{\mathrm{m}}$ of the lipase were 3,1900 $\mathrm{U} / \mathrm{mg}$ and $0,2428 \mathrm{mM}$, respectively. The enzyme activity of lipase was stable up to $45^{\circ} \mathrm{C}$ for $10 \mathrm{~min}$.

Keywords: Marinobactersp, lipase, response surface methodology, p-nitrofenil palmitate.

\section{INTRODUCCIÓN}

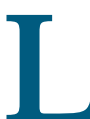

as enzimas microbianas de interés industrial presentan ventajas de reacción - frente a los catalizadores químicos - y usos en diferentes procesos biotecnológicos limpios y sostenibles. Así, el 9o\% de enzimas industriales son producidas por fermentación microbiana ${ }^{(1)}$.

Las lipasas (triacilglicerol éster hidrolasas, EC 3.1.1.3) son enzimas ampliamente distribuidas en la naturaleza, desde microorganismos hasta plantas y animales. La actividad más reconocida de las lipasas es la hidrólisis de triacilgliceroles (grasas y aceites) que produce ácidos grasos y glicerol. Además, estas enzimas catalizan reacciones in vitro, tales como esterificación, transesterificación e interesterificación en medios hidrofóbicos; son estables en solventes orgánicos; presentan amplia especificidad por sustrato y elevada regioselectividad o estereoselectividad en la catálisis ${ }^{(2)}$.

Las lipasas, por sus diversas propiedades catalíticas, se usan en la elaboración de detergentes, en las industrias, farmacéutica, textil, cosmética, química, papelera, entre otras. En los últimos años, estas enzimas se emplean en la síntesis de biopolímeros y biodiesel, en la producción de medicamentos enantioselectivos, agroquímicos y aromatizantes ${ }^{(1,3)}$. Sin embargo, solo algunas lipasas microbianas son comercialmente explotadas, en consecuencia, se requiere el continuo estudio de lipasas nativas que presenten amplio rango de sustratos, elevada enantioselectividad y estabilidad ${ }^{(4)}$. 
Las bacterias halófilas se caracterizan por su tolerancia a elevadas concentraciones salinas y pH alcalino. Así, del género Marinobacter, se ha descrito actividad lipolítica en $M$. lypoliticus y $M$. hydrocarbonoclasticus; pero no se ha reportado la caracterización de la lipasa de Marinobacter sp., bacteria halófila moderada, aislada de las salinas de Pilluana, localizada al nororiente del Perú, que ha demostrado actividad lipolítica frente a diferentes triglicéridos ${ }^{(5,6)}$.

El objetivo de la presente investigación fue caracterizar parcialmente los parámetros cinéticos y factores que afectan la actividad de una lipasa extracelular de Marinobacter sp. utilizando la metodología de superficie respuesta.

\section{MATERIALES Y MÉTODOS}

\section{Obtención del crudo enzimático}

Se utilizó Marinobacter sp., bacteria halófila moderada Gram negativa aislada de las salinas de Pilluana (San Martín) ${ }^{(6)}$, perteneciente al cepario de microorganismos del Laboratorio de Biología Molecular de la Facultad de Farmacia y Bioquímica de la Universidad Nacional Mayor de San Marcos. La bacteria se cultivó en medio agua de sales (SW) conteniendo cloruro de sodio $5 \%$, suplementado con extracto de levadura $0,5 \%$, así como aceite de oliva $1 \%$ y Triton X-10o 0,1\% como inductor y emulgente, respectivamente. A $100 \mathrm{~mL}$ del medio SW se añadieron $5 \mathrm{~mL}$ del cultivo bacteriano en frascos Erlenmeyer de $1 \mathrm{~L}$, luego se incubó a $37{ }^{\circ} \mathrm{C}$ por 8 horas a $200 \mathrm{rpm}$. La biomasa bacteriana se separó del sobrenadante por centrifugación a $5000 \mathrm{rpm}$ a $4{ }^{\circ} \mathrm{C}$ durante $10 \mathrm{~min}$. El sobrenadante obtenido constituyó el extracto crudo, el mismo que fue filtrado en gradiente en membranas de acetato de celulosa de o,45 y o,22 mm, se concentró 5 veces $(5 \mathrm{X})$ usando un sistema de ultrafiltración tangencial (Millipore, Alemania) con un cassette de corte molecular $10 \mathrm{kDa}$, el proceso de filtración y concentración se realizó a $4{ }^{\circ} \mathrm{C}$. La muestra concentrada fue dializada en agua destilada durante 8 horas a $10^{\circ} \mathrm{C}$ y se guardó a $-20^{\circ} \mathrm{C}$.

\section{Determinación de la actividad enzimática}

La actividad hidrolítica de la lipasa fue evaluada empleando como sustrato el p-nitrofenil palmitato (p-NPP) de la casa Sigma, siguiendo la metodología propuesta por Gupta y col. ${ }^{(8)}$, con las siguientes modificaciones: a 1,6 mg de p-NPP se añadió $1 \mathrm{~mL}$ de isopropanol; o,1 mL de Triton X-10o y buffer fosfato 25
$\mathrm{mM} \mathrm{pH} 7$ hasta completar $10 \mathrm{~mL}$. Para la determinación de la actividad enzimática se emplearon 1,75 mL de la solución antes descrita y o, $25 \mathrm{~mL}$ del crudo enzimático conteniendo la lipasa. La mezcla se incubó por 20 min a $37^{\circ} \mathrm{C}$. La hidrólisis del p-NPP por la lipasa fue determinada por incremento del p-nitrofenol a 410 $\eta \mathrm{m}$. Una unidad de actividad enzimática se definió como la cantidad de enzima necesaria para liberar 1 $\mu$ mol de p-nitrofenol en un min.

\section{Determinación de proteínas}

Se utilizó el reactivo de Bradford siguiendo la metodología propuesta por Amresco, empleando como estándar albúmina sérica bovina (BSA), a las concentraciones de 125, 250, 500, 750 y $1000 \mu \mathrm{g} / \mathrm{mL}$.

\section{Factores que influyen en la actividad de la lipasa}

Se ensayaron los efectos de temperatura, $\mathrm{pH}$, tiempo, concentraciones de cloruro de sodio y calcio, sobre la actividad de la lipasa presente en el extracto crudo, empleando la Metodología de Superficie Respuesta (MRS), con el fin de analizar 5 variables a tres niveles para lo cual se empleó el Diseño Estadístico Experimental (DEE) Box-Behnken, usando el programa Minitab 16, con un total de 40 experimentos y 6 réplicas en el punto central.

\section{Determinación de $K_{m}$ y $\mathbf{V}_{\text {max }}$}

La actividad de la lipasa en el extracto crudo se determinó a condiciones óptimas de $\mathrm{pH}$ 7,0 y temperatura de $37,0^{\circ} \mathrm{C}$, a concentraciones de p-NPP entre o,o y o,6 mM, manteniendo la concentración de enzima constante. $\mathrm{La}_{\mathrm{m}}$ y $\mathrm{V}_{\max }$ se determinaron a partir de la curva de dobles recíprocas.

\section{Termoestabilidad de la lipasa}

Se pre incubaron alícuotas de $0,1 \mathrm{~mL}$ de extracto concentrado a $37,40,45,50,60,70$ y $100{ }^{\circ} \mathrm{C}$ durante $10 \mathrm{~min}$. Después, las muestras se enfriaron e inmediatamente se midieron sus actividades, los resultados fueron expresados en actividades residuales determinadas a $37^{\circ} \mathrm{C}$ y pH 7,o.

\section{RESULTADOS}

En la tabla 1 se presentan las actividades enzimáticas y específicas de la lipasa de Marinobacter sp. según el diseño experimental de Box-Behnken. Las variables y sus valores seleccionados fueron: $\mathrm{pH}(4,0$; 7,0 y 9,0 ), temperatura $\left(5,0 ; 32,5\right.$ y $45,0^{\circ} \mathrm{C}$ ), tiempo (o, 20 y $40 \mathrm{~min}$ ), concentraciones de $\mathrm{NaCl}$ (o,0; 5,0 y 10,0 \%) y $\mathrm{CaCl}_{2}(0,0 ; 0,05$ y o,1\%). 
Los efectos individuales de los factores analizados frente a sus respectivas respuestas en actividad específica se presentan en la figura 1. Para este análisis se mantuvieron los parámetros medios como óptimos.

En la figura 2, se presentan las gráficas de contorno que permiten visualizar las superficies de respuesta para el diseño experimental planteado, así en cada gráfica se observa la actividad específica frente a dos factores a la vez, manteniendo los demás fijos a valores medios, la zona más oscura indica la máxima respuesta para cada caso.

Según el análisis de varianza, el modelo de regresión es significativo ( $p=0$, oo 4 ), loque indica que por lo menos uno de los términos en la ecuación tiene impacto sobre la respuesta media de la actividad específica de la lipasa, y se identifica como significativo al término cuadrático $(p=0,031)$ El modelo contiene una sola interacción de dos factores para tiempo y $\mathrm{NaCl}(p=o, o 38)$.

La $\mathrm{K}_{\mathrm{m}} \mathrm{y}_{\text {max }}$ fueron determinadas con la gráfica de Lineweaver Burk, siendo o,2428 mMy3,19 U/mg, respectivamente, utilizando p-NPP como sustrato.

La determinación de la resistencia a la inactivación térmica de la lipasa de Marinobacter sp. se presenta en la figura 3, la estabilidad se mantuvo hasta los 45 ${ }^{\circ} \mathrm{C}$, disminuyendo por encima de los 50 ${ }^{\circ} \mathrm{C}$, hasta perder la actividad a $70^{\circ} \mathrm{C}$.

\section{DISCUSIÓN}

El extracto crudo conteniendo la lipasa de Marinobacter sp. demostró tener actividad hidrolítica sobre el p-NPP en un rango de temperatura entre $10 \mathrm{y}$ $45{ }^{\circ} \mathrm{C}$ siendo la óptima de $37^{\circ} \mathrm{C}$ (Figura 1A). La actividad específica disminuyó por encima de $38{ }^{\circ} \mathrm{C}$ de 0,8 a o,7 $\mathrm{U} / \mathrm{mg}$; pero no disminuyó totalmente, por lo que se infiere que el rango de actividad de la enzima aún puede ser mayor a la descrita. Así las lipasas de Candida rugosa, presentan actividad lipolítica entre 20 y $65^{\circ} \mathrm{C}$, con rangos óptimos entre
Tabla 1. Factores que influyen en la actividad enzimática y específica de la lipasa extracelular de Marinobacter sp., según diseño estadístico experimental Box-Behnken de superficie respuesta.

\begin{tabular}{|c|c|c|c|c|c|c|c|}
\hline \multirow{2}{*}{$\begin{array}{c}\mathbf{N}^{\circ} \\
\text { Experimento }\end{array}$} & \multicolumn{5}{|c|}{ Factores } & \multirow{2}{*}{$\begin{array}{c}\text { Act. } \\
\text { Enzimática } \\
\text { (umol/ } \\
\text { minx ml) }\end{array}$} & \multirow{2}{*}{$\begin{array}{c}\text { Act. } \\
\text { Específica } \\
\text { (U/mg } \\
\text { proteína) }\end{array}$} \\
\hline & pH & $\mathrm{T}\left({ }^{\circ} \mathrm{C}\right)$ & $\begin{array}{c}\text { Tiempo } \\
\text { (min) }\end{array}$ & $\begin{array}{l}\mathrm{NaCl} \\
(\%)\end{array}$ & $\begin{array}{c}\mathrm{CaCl}_{2} \\
(\%)\end{array}$ & & \\
\hline 1 & 9,0 & 32,5 & 20 & 10 & 0,05 & 0,0435 & 0,2072 \\
\hline 2 & 7,0 & 32,5 & 20 & 10 & 0,00 & 0,2135 & 1,0168 \\
\hline 3 & 7,0 & 32,5 & 40 & 0 & 0,05 & 0,8378 & 3,9893 \\
\hline 4 & 7,0 & 45,0 & 20 & 5 & 0,10 & 0,0000 & 0,0000 \\
\hline 5 & 7,0 & 32,5 & 20 & 5 & 0,05 & 0,7018 & 1,8565 \\
\hline 6 & 4,0 & 32,5 & 0 & 5 & 0,05 & 0,0000 & 0,0000 \\
\hline 7 & 9,0 & 32,5 & 20 & 0 & 0,05 & 0,3074 & 0,8131 \\
\hline 8 & 7,0 & 32,5 & 20 & 5 & 0,05 & 0,5984 & 1,5831 \\
\hline 9 & 9,0 & 32,5 & 40 & 5 & 0,05 & 0,1863 & 0,8872 \\
\hline 10 & 7,0 & 5,00 & 20 & 0 & 0,05 & 0,0000 & 0,0000 \\
\hline 11 & 4,0 & 32,5 & 40 & 5 & 0,05 & 0,0048 & 0,0227 \\
\hline 12 & 7,0 & 45,0 & 20 & 10 & 0,05 & 0,1768 & 0,8419 \\
\hline 13 & 7,0 & 5,00 & 40 & 5 & 0,05 & 0,0000 & 0,0000 \\
\hline 14 & 7,0 & 45,0 & 20 & 0 & 0,05 & 0,3182 & 1,5154 \\
\hline 15 & 7,0 & 5,00 & 0 & 5 & 0,05 & 0,0000 & 0,0000 \\
\hline 16 & 7,0 & 5,00 & 20 & 10 & 0,05 & 0,0000 & 0,0000 \\
\hline 17 & 4,0 & 5,00 & 20 & 5 & 0,05 & 0,0000 & 0,0000 \\
\hline 18 & 7,0 & 32,5 & 40 & 5 & 1,00 & 0,2604 & 1,2402 \\
\hline 19 & 9,0 & 32,5 & 20 & 5 & 0,00 & 0,1523 & 0,7253 \\
\hline 20 & 4,0 & 32,5 & 20 & 0 & 0,05 & 0,0136 & 0,0648 \\
\hline 21 & 7,0 & 32,5 & 0 & 0 & 0,05 & 0,1224 & 0,3238 \\
\hline 22 & 7,0 & 5,00 & 20 & 5 & 0,00 & 0,0000 & 0,0000 \\
\hline 23 & 7,0 & 32,5 & 0 & 10 & 0,05 & 0,0408 & 0,1079 \\
\hline 24 & 4,0 & 45,0 & 20 & 5 & 0,05 & 0,0000 & 0,0000 \\
\hline 25 & 7,0 & 32,5 & 20 & 5 & 0,05 & 0,3835 & 1,8263 \\
\hline 26 & 7,0 & 32,5 & 20 & 10 & 0,10 & 0,1414 & 0,6735 \\
\hline 27 & 4,0 & 32,5 & 20 & 5 & 0,10 & 0,0163 & 0,0777 \\
\hline 28 & 7,0 & 32,5 & 20 & 5 & 0,05 & 0,3441 & 1,6385 \\
\hline 29 & 9,0 & 45,0 & 20 & 5 & 0,05 & 0,6922 & 3,2964 \\
\hline 30 & 4,0 & 32,5 & 20 & 5 & 0,00 & 0,0503 & 0,2396 \\
\hline 31 & 7,0 & 45,0 & 40 & 5 & 0,05 & 0,1489 & 0,7091 \\
\hline 32 & 7,0 & 32,5 & 20 & 5 & 0,05 & 0,3441 & 1,6385 \\
\hline 33 & 9,0 & 32,5 & 0 & 5 & 0,05 & 0,0000 & 0,0000 \\
\hline 34 & 4,0 & 32,5 & 20 & 10 & 0,05 & 0,0163 & 0,0777 \\
\hline 35 & 7,0 & 32,5 & 20 & 0 & 0,10 & 0,2026 & 0,9650 \\
\hline 36 & 7,0 & 45,0 & 0 & 5 & 0,05 & 0,0000 & 0,0000 \\
\hline 37 & 7,0 & 32,5 & 40 & 5 & 0,00 & 0,2740 & 1,3050 \\
\hline 38 & 7,0 & 5,00 & 20 & 5 & 0,10 & 0,0000 & 0,0000 \\
\hline 39 & 7,0 & 45,0 & 20 & 5 & 0,00 & 0,2530 & 1,2046 \\
\hline 40 & 7,0 & 32,5 & 0 & 5 & 0,10 & 0,0490 & 0,2331 \\
\hline 41 & 9,0 & 5,00 & 20 & 5 & 0,05 & 0,0000 & 0,0000 \\
\hline 42 & 7,0 & 32,5 & 20 & 0 & 0,00 & 0,7793 & 3,7109 \\
\hline 43 & 7,0 & 32,5 & 40 & 10 & 0,05 & 0,1428 & 0,6800 \\
\hline 44 & 9,0 & 32,5 & 20 & 5 & 1,00 & 0,1428 & 0,6800 \\
\hline 45 & 7,0 & 32,5 & 20 & 5 & 0,05 & 0,3876 & 1,8457 \\
\hline 46 & 7,0 & 32,5 & 0 & 5 & 0,00 & 0,0544 & 0,2590 \\
\hline
\end{tabular}




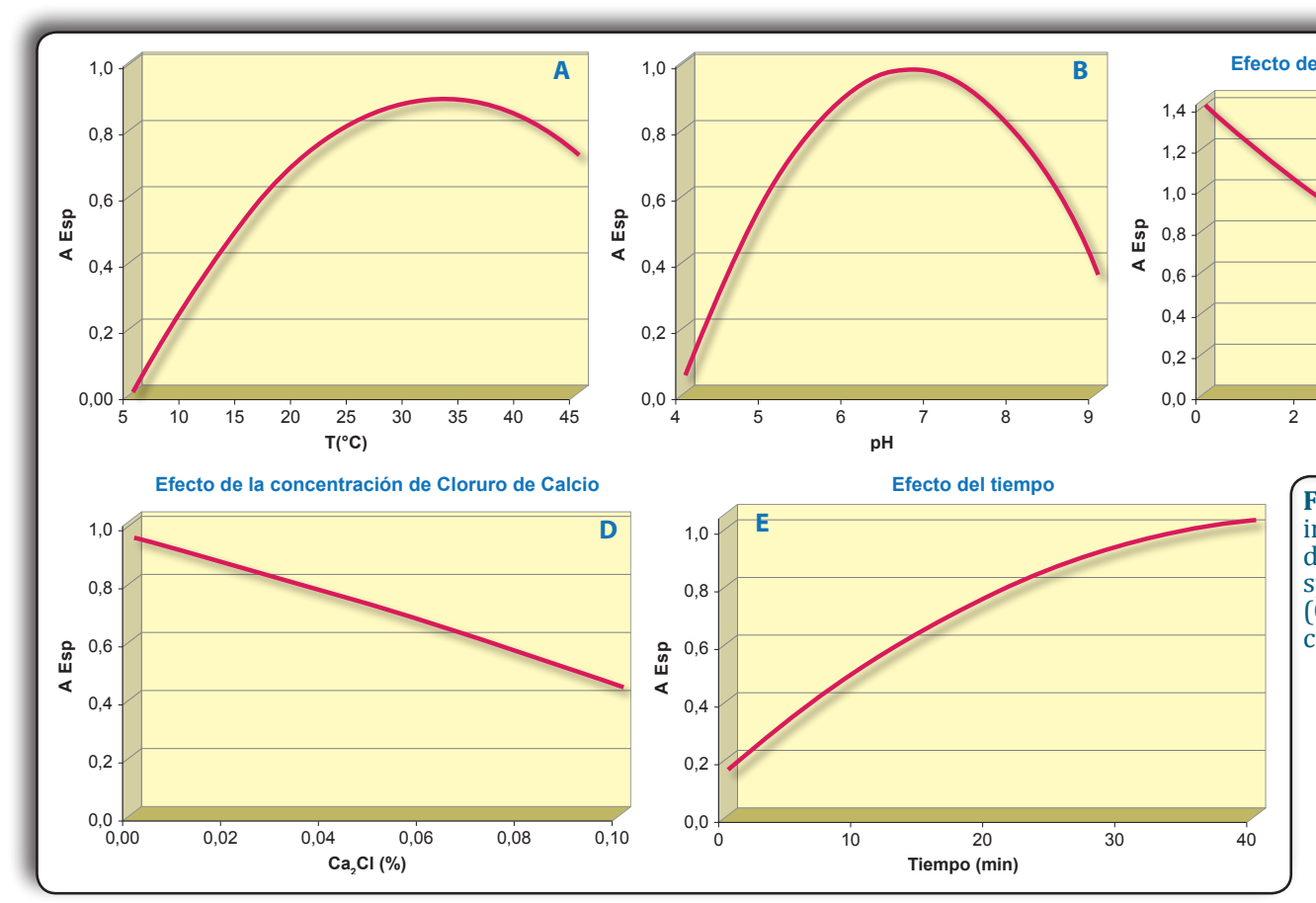

fecto de la concentración de Cloruro de Sodio

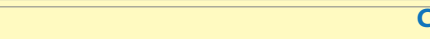

Efecto de la concentración de Cloruro de Calcio

Figura 1. Efectos de los factores que influyen sobre la actividad específica de la lipasa de Marinobacter sp.: (A) Temperatura, (B) $\mathrm{pH}$, (C) concentración de $\mathrm{NaCl}$, (D) concentración de $\mathrm{CaCl}_{2}$ y (E) tiempo.

Según lodescrito por Ozürk ${ }^{(10)}$, la activación o inhibición producida por ciertos iones depende del sustrato empleado, la

30 a $50^{\circ} \mathrm{C}{ }^{(9-11)}$. Esta estabilidad térmica de las lipasas se debe al alto contenido de aminoácidos hidrofóbicos, ya que proveen una estructura compacta que evita que la enzima se desnaturalice ante cambios térmicos. Además, Gonzáles-Bacerio y col. ${ }^{(9)}$, han reportado que la pureza de la enzima también influye en la temperatura óptima, de modo que las lipasas presentes en preparados crudos, con altas concentraciones de otras proteínas son más estables y exhiben valores mayores al rango óptimo.

La lipasa de Marinobacter sp. demostró actividad catalítica a pH de 5,o y 9,o con un pH óptimo de 7,o a 37 ${ }^{\circ} \mathrm{C}$, el cual está en el rango descrito para lipasas de origen microbiano que presentan mayor actividad entre los $\mathrm{pH}$ 7,o y 8,o. Gonzáles-Bacerio y col. ${ }^{(9)}$, describen que las condiciones óptimas de $\mathrm{pH}$ dependen del sustrato y tampón empleado, cuando la actividad enzimática se ensaya frente a sustratos específicos como aceite de oliva, tributirina, trioleína y triacilglicéridos.

Al respecto Martínycol. ${ }^{(12)}$ reportaronelcrecimiento óptimo de Marinobacter lipolyticus a $\mathrm{pH}$ 7,5. En estudios posteriores, Pérez y col. ${ }^{(3)}$ aislaron y purificaron la lipasa Lip BL, que presentó actividad hidrólitica a pH entre 6,0 y 10,o hallándose el óptimo a pH 7,o.

Por otro lado, se investigaron los efectos de los cationes $\mathrm{Na}^{+}$y Ca${ }^{2+}$ en la actividad de la enzima, ya que han sido descritos como activadores de la actividad de varias lipasas, contrariamente al calcio y sodio que disminuyen la actividad de la lipasa de Marinobacter sp. (figuras $1 C$ y $1 D$ ). fuente de enzima y las condiciones del ensayo. Así el calcio incrementa la actividad de muchas lipasas que emplearon como sustrato el aceite de oliva al producir un cambio conformacional en la enzima, con lo cual se potencia la unión de la lipasa a la interfase agua-aceite.

Por lo descrito previamente, la disminución de la actividad de hidrólisis del p-NPP por la lipasa de Marinobacter sp. al incrementar la concentración del $\mathrm{Ca}^{2+}$ se puede explicar por el tipo de sustrato empleado.

Las gráficas de contorno (figura 2) permiten observar interacciones entre los factores y la actividad máxima de la lipasa de Marinobacter sp. cuando se varían simultáneamente: $\mathrm{pH}$ y concentración de $\mathrm{CaCl}_{2}$ (figura 2A), temperatura y concentración de $\mathrm{CaCl}_{2}$ (figura $2 \mathrm{~B}$ ), tiempoyconcentración de $\mathrm{CaCl}_{2}$ (figura $2 \mathrm{C}$ ). La actividad máxima fue mayor a 1,6 U/mg a $\mathrm{pH}$ entre 7,0 y 8,0 ; a $37^{\circ} \mathrm{C}$ y $30 \mathrm{~min}$, en los tres casos cuando las concentraciones de cloruro de calcio fueron menores a $0,04 \%$. Además, se observa que a medida que se incrementa el calcio, la actividad específica disminuye. El análisis ANOVA $(p>0,05)$ confirma los resultados, ya que no existen interacciones significativas entre las variaciones de las concentraciones de cloruro de calcio, con el $\mathrm{pH}$, temperatura y tiempo.

A medida que se incrementa el tiempo y la temperatura, la actividad específica aumenta, presentando su valor máximo (mayor a $2 \mathrm{U} / \mathrm{mg}$ ) por 


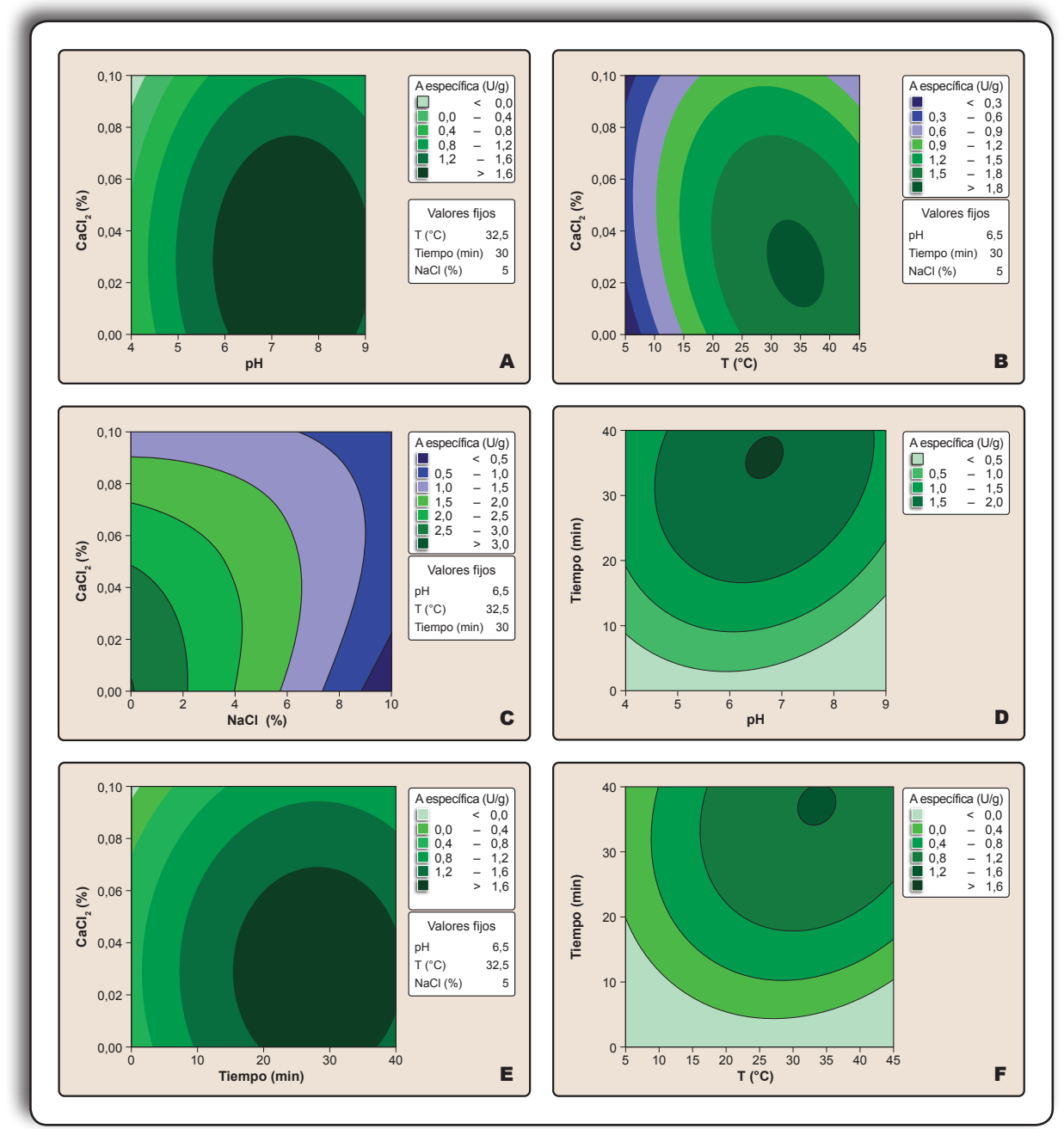

Figura 2. Gráficas de contorno de dos factores y la actividad específica de la lipasa de Marinobacter sp. A) $\mathrm{CaCl}_{2}$ y pH; B) $\mathrm{CaCl}_{2}$ y temperatura; C) $\mathrm{CaCl}_{2}$ y $\mathrm{NaCl}$; D) Tiempo y pH; E) Tiempo y $\mathrm{CaCl}_{2}$; F) Temperatura y tiempo.

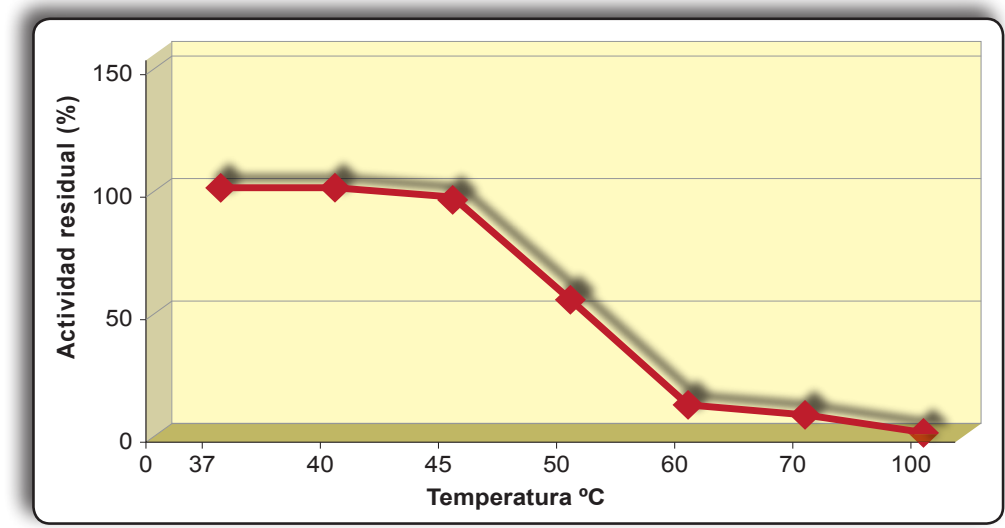

Figura 3. Termoestabilidad de la lipasa extracelular de Marinobacter sp.

encima de los $35^{\circ} \mathrm{C}$ y $30 \mathrm{~min}$. Comportamiento similar al anterior se observa cuando se varía el tiempo y el $\mathrm{pH}$, con valor máximo a $\mathrm{pH}$ 7,o por encima de 30 min.
De acuerdo al análisis de varianza el $\mathrm{pH}(p=0,03) ; \mathrm{pH}^{*} \mathrm{pH}$ $(p=0,005), \mathrm{T}\left({ }^{\circ} \mathrm{C}\right) * \mathrm{~T}\left({ }^{\circ} \mathrm{C}\right)(p=0,024)$, tiempo*tiempo $(p=0,02)$, son los factores más significativos sobre la actividad específica del crudo enzimático; además el valor $p$, para determinar si existe o no interacción entre los diferentes factores no fue significativo $(p=0,262)$, con una sola interacción de dos factores para tiempo ${ }^{*} \mathrm{NaCl}$ con un valor de $p<0,05$, por lo que el efecto del tiempo en la actividad específica de la enzima varía con la concentración de cloruro de sodio.

La $\mathrm{V}_{\max }$ y $\mathrm{K}_{\mathrm{m}}$ fueron 0,325 $\mathrm{U} / \mathrm{mg}$ proteína y $2,29 \mathrm{mM}$, respectivamente. Al respecto se ha descrito que la $\mathrm{K}_{\mathrm{m}}$ y $\mathrm{V}_{\max }$ varían con el tipo de sustrato y con la fuente enzimática. En este sentido, González-Bacerio (9), reportan el efecto de la concentración de sustrato sobre la actividad enzimática ensayando en diferentes sustratos y enzimas de diversas fuentes, así la $\mathrm{K}_{\mathrm{m}}$ de la lipasa de Candida rugosa, utilizando p-nitrofenil butirato y aceite de oliva, fue de $0,0392 \mathrm{mM}$, respectivamente.

La lipasa de Marinobacter sp., contenida en el extracto crudo, se mantuvo estable hasta $45^{\circ} \mathrm{C}$, cuando se empleó el p-NPP como sustrato. A $50{ }^{\circ} \mathrm{C}$ la enzima pierde la mitad de su actividad $\left(\mathrm{T}_{50}\right)$. La estabilidad de esta lipasa fue comparable a la obtenida por Benjamin y Pandey ${ }^{(14)}$, quienes describen la estabilidad entre 35 y $40{ }^{\circ} \mathrm{C}$, de tres lipasas obtenidas de $C$. rugosa DMS 203. Por otro lado, Ruiz y col. (15) ensayaron la estabilidad de la lipasa de Penicillium candidum por incubación a diferentes temperaturas durante $10 \mathrm{~min}$, la enzima mantuvo su actividad entre 25 y $35^{\circ} \mathrm{C}$, y la perdió a $75{ }^{\circ} \mathrm{C}$. La estabilidad de la lipasa purificada Lip BL de Marinobacter lipolyticus SM19 mostró disminución del 35 , 80 y $90 \%$ a los 45 , 50 y $60^{\circ} \mathrm{C}$, respectivamente, después de una hora de incubación. 


\section{CONCLUSIÓN}

Secaracterizó parcialmenteuna lipasa extracelular de Marinobacter sp. mediante la metodología de superficie respuesta y se determinó que los factores que influyen en su actividad de hidrólisis del p-NPP fueron $\mathrm{pH}$ y tiempo. Los parámetros óptimos fueron $\mathrm{pH} 7,0 ; 37^{\circ} \mathrm{C}$ y $30 \mathrm{~min}$. La estabilidad de la enzima se mantuvo entre 20 y $45^{\circ} \mathrm{C}$.

Agradecimientos: Este trabajo fue financiado parcialmente por contrato o17/FINCYT/PIBAP/2008 y por el contrato de Subvención $\mathrm{N}^{\circ}$ 031-2011- CONCYTEC - OAJ.

\section{REFERENCIAS BIBLIOGRÁFICAS}

1. Jaeger K-E, Dijkstra BW, Reetz MT. Bacterial biocatalysts: molecular biology, three-dimensional structures and biotechnological applications of lipases. Annu Rev Microbiol 1999; 53: 315-51.

2. Jaeger KE, Ransac S, Dijkstra BW, Colson C, Van Heuvel $M$ van, Misset O. Bacterial lipases. FEMS Microbiol Rev 1994; 15(1): 29-63.

3. Jaeger KE, Eggert T. Lipases for biotechnology. Curr Opin Biotechnol 2002; 13(4): 390-7.

4. Sharma D, Sharma B, Shukla AK, Biotechnological approach of microbial lipase: A review. Biotech 2011; 10: 23-40.

5. Neelambari V, Vasanthabharathi V, Balasubramanian R, Jayalakshmi S. Lipase from marine Aeromonas hydrophila. Res J Microbiol 2011; 6 ( 8): 658-668.

6. Chávez Hidalgo E. Bacterias halófilas moderadas con actividad lipolítica aisladas de las salinas de Pilluana San Martín. [Tesis para obtener el grado de Magister]. Facultad de Farmacia y Bioquímica. Universidad Nacional Mayor de San Marcos. 2010.

7. Alejandro Paredes A. Producción en cultivo discontinuo y caracterización parcial de lipasas de Marinobacter sp. aislada de las salinas de Pilluana. [Tesis para obtener el título de Químico Farmacéutico]. Facultad de Farmacia y bioquímica. Universidad Nacional Mayor de San Marcos. Lima, 2012.

8. Gupta R, Rathi P, Gupta N, Bradoo S. Lipase assays for conventional and molecular screening: an overview. Biotechnol Appl Biochem 2003; 37(Pt 1): 63-71.

9. González-Bacerio J, Rodríguez Hernández J, Del Monte Martínez A. Las lipasas: enzimas con potencial para el desarrollo de biocatalizadores inmovilizados por adsorción interfacial. Rev Colomb Biotecnol 2010; 12(1): 124-40.

10. Ozürk B. Immobilization of lipase from Candida rugosa on hydrophobic and hydrophilic supports. [Tesis de maestría]. Departamento de Biotecnología. Universidad de Turquía. 2001.

11. Arroyo M. Inmovilización de enzimas. Fundamentos, métodos y aplicaciones. Ars Pharmaceutica 1998; 39(2).

12. Martín S, Márquez M, Sánchez-Porro C, Mellado E, Arahal D,Ventosa A. Marinobacter lipolyticus sp. nov., a novel moderate halophile with lipolytic activity. Int J Syst Evol Microbiol. 2003; 53: 1383-1390.

13. Pérez D, Martín S, Fernández-Lorente G, Filice M, Guisán JM, et al. A novel halophilic lipase, LipBL, showing high efficiency in the production of eicosapentaenoic acid (EPA). PLoS ONE 2011; 6(8): e23325.

14. Benjamin S, Pandey A. Candida rugosa lipases: molecular biology and versatility in biotechnology. Yeast 1998; 14(12): 1069-87.

15. Ruiz B, Farrés A, Langley E, Masso F, Sánchez F. Purification and characterization of an extracellular lipase from Penicillium candidum. Lipids 2001; 36(3): 283-9.

\section{Correspondencia}

Nombre: Yadira Fernández Jerí

Dirección: Jr. Puno 1002 - Lima 1 - Perú

E-mail: yfernandezj@unmsm.edu.pe 